\title{
STUDIES IN PARA-AMINOHIPPURIC ACID SYNTHESIS IN THE HUMAN : ITS APPLICATION AS A LIVER FUNCTION TEST
}

\author{
By WILliaM P. DEISS ANd PHILIP P. COHEN
}

\author{
(From the Departments of Medicine and Physiological Chemistry, University of Wisconsin \\ Medical School, Madison, Wisconsin)
}

(Submitted for publication February 24, 1950; accepted, April 17, 1950)

Synthesis of p-aminohippuric acid (PAH) from $\mathrm{p}$-aminobenzoic acid $(\mathrm{PAB})$ in animal liver slices and homogenates has been shown to resemble closely, both chemically and thermodynamically, the synthesis of peptides (1-3). This reaction has been utilized in the hippuric acid synthesis test for liver function since 1933 (4) and has found wide clinical application (5-7). Hippuric acid, however, must be determined in the urine and, consequently, relatively normal renal excretion is necessary. The actual determination is tedious since it involves precipitation, drying, and weighing of the excreted hippuric acid and analysis by titration, and is subject to considerable technical error.

Study of the metabolism of PAB has been somewhat complicated by the difficulty in separating it from the conjugated form, $\mathrm{PAH}$, in body fluids. Using ethylene dichloride extraction of $\mathrm{PAB}$, it has been shown that excretion of free PAB, PAH, and the acetylated forms follows the oral administration of PAB in the human (8). Ether extraction of $\mathrm{PAB}$ and quantitative determination of the fractions by the usual diazo reaction for sulfonamides were used in the studies of PAH synthesis in tissue homogenates $(1,2)$. Using modifications of the latter method for serum and urine, the present study was conducted to investigate further the synthesis of PAH in the human and the possibility of utilizing this synthesis as a liver function test.

\section{CLINICAL MATERIAL AND PROCEDURE}

Subjects for these studies were two groups of patients from the wards of the State of Wisconsin General Hospital. The first group consisted of 60 adults of various ages with neither primary nor secondary liver disease. Fourteen of these were organically sound and 46 had various organic diseases without liver involvement. This group was taken as normal. The second group consisted of 34 patients with primary or secondary liver disease or impairment and seven patients with obstructive jaundice.
All the subjects received $3 \mathrm{~g}$. of sodium PAB (in the commercial tablet form with a starch filler) orally at least two hours after a light breakfast. On separate occasions 14 subjects, eight of the normal group and six of the liver impairment group, were given $25 \mathrm{ml}$. of a $20 \%$. solution of Glycine, N.F. in addition to the oral sodium PAB. One normal subject was given $0.8 \mathrm{~g}$. of sodium benzoate intravenously ten minutes before the oral dose of sodium PAB.

Five ml. blood samples were withdrawn at regular intervals after administration of sodium $\mathrm{PAB}$ and in two normal subjects four hourly total urine specimens were collected.

\section{METHODS}

\section{Determination in serum}

Preparation of sample: One $\mathrm{ml}$. of serum was deproteinized with $4 \mathrm{ml}$. of $0.5 \mathrm{~N}$ trichloroacetic acid. Following centrifugation, appropriate aliquots of the supernatant, of the order of $0.5 \mathrm{ml}$. and $1 \mathrm{ml}$., were accurately measured into colorimeter tubes for analysis of total PAB + PAH.

Extraction of $P A B$ : To $1 \mathrm{ml}$. of the supernatant accurately measured into a $60 \mathrm{ml}$. bottle was added $2 \mathrm{ml}$. of buffer (made by adding $0.25 \mathrm{M}$ citric acid to $0.5 \mathrm{M}$ disodium phosphate to give $\mathrm{pH} 3.85$ upon dilution of 2 $\mathrm{ml}$. with $1 \mathrm{ml}$. of distilled water; $5 \mathrm{~N}$ sodium hydroxide was added to the buffer in an amount equivalent to the trichloroacetic acid in $1 \mathrm{ml}$. of the supernatant so that the $\mathrm{pH}$ remained 3.85 upon addition of $2 \mathrm{ml}$. of buffer to $1 \mathrm{ml}$. of supernatant). Ten $\mathrm{ml}$. of ether, saturated with distilled water and allowed to stand overnight, were added to the bottle which was then stoppered with a cork and a short length of glass tubing, and shaken in a mechanical shaker for three minutes at 200 oscillations/ min. with a $5 \mathrm{~cm}$. throw at the top of the bottle. The ether was then aspirated with a capillary pipette, following which $10 \mathrm{ml}$. of additional ether were added and the shaking repeated for three minutes. The ether was again aspirated. Fifteen $\mathrm{ml}$. of benzene were added and the bottle again shaken for two minutes. (The optimal time of shaking varies somewhat with the shaker. The distribution ratio of $\mathrm{PAH} / \mathrm{PAB}$ remaining after extraction should be determined for each shaker.) Two $\mathrm{ml}$. of the aqueous phase were then pipetted into a colorimeter tube for PAH analysis.

Colorimetric analysis: The total volume in the colorimeter tubes was brought to $10 \mathrm{ml}$. with $0.1 \mathrm{~N} \mathrm{HCl}$. One 
ml. of each of the following was added with shaking at three minute intervals: (1) $0.1 \%$ c. p. sodium nitrite, (2) $0.5 \%$ ammonium sulfamate, and (3) $0.1 \% \mathrm{~N}-$ (1naphthyl) ethylenediamine $\mathrm{HCl}$. After 10 minutes solutions were compared against a reagent blank in a spectrophotometer at $540 \mathrm{~m} \mu$ and the amounts (as PAH) determined from a calibration curve.

Calculations: Since $1 \%$ of the PAB and $86 \%$ of the $\mathrm{PAH}$ remain after extraction with our shaker and the total $\mathrm{PAB}+\mathrm{PAH}$ is known by analysis, the true value for

$$
\mathrm{PAH}=\frac{\mathrm{E}-.01 \mathrm{~T}}{0.85}
$$

where $E=$ the total after extraction in $\mu \mathrm{M} / \mathrm{ml}$. serum and $\mathrm{T}=$ the total $\mathrm{PAB}+\mathrm{PAH}$ or the total before extraction in $\mu \mathrm{M} / \mathrm{ml}$. serum. The per cent of the total $\mathrm{PAB}+\mathrm{PAH}$ in the conjugated form can be calculated from this:

$$
\% \text { PAH (subject's) }=\frac{E-.01 \mathrm{~T}}{0.85 \mathrm{~T}} \times 100 .
$$

As will be shown (see Figure 2) the \% PAH in normal sera at one hour bears a consistent inverse relationship to the total PAB + PAH. The normal mean \% PAH can be calculated for any level of total PAB + PAH by the formula:

$$
\% \text { PAH (normal mean })=\frac{1.9-T}{5 T+2} \times 100 .
$$

Thus, the subject's \% PAH value $\times 100$ divided by

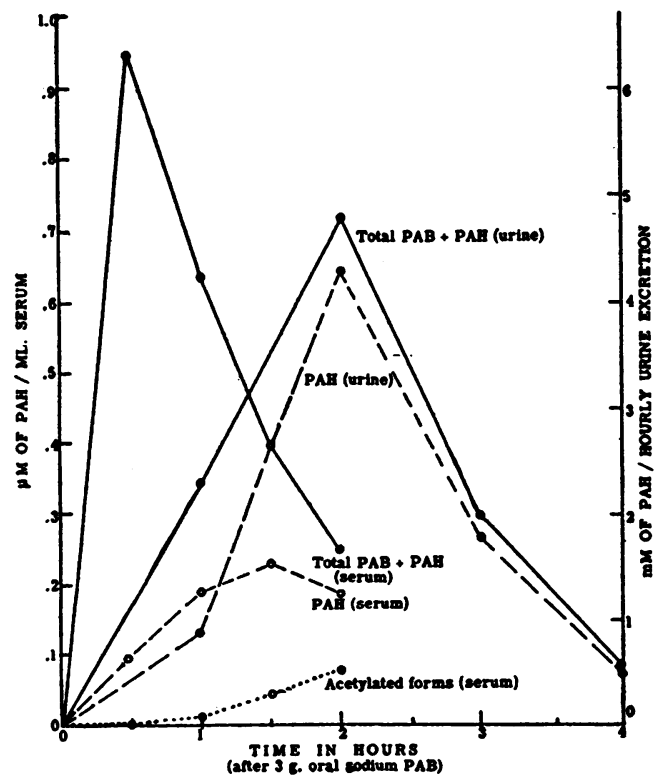

A the normal mean \% PAH value becomes:

Subject's PAH synthesis in \% of normal mean

$$
=\frac{(\mathrm{E}-.01 \mathrm{~T})(5 \mathrm{~T}+2)}{0.85 \mathrm{~T}(1.9-\mathrm{T})} \times 100 \text {. }
$$

Determination of acetylation: Five $\mathrm{ml}$. of the deproteinized supernatant was boiled with $0.25 \mathrm{ml}$. of $4 \mathrm{~N}$ $\mathrm{HCl}$ for one hour in a water bath. The solution was then cooled and brought to $5 \mathrm{ml}$. with distilled water. One ml. of this solution was then brought to $10 \mathrm{ml}$. with $0.1 \mathrm{~N}$ $\mathrm{HCl}$ and the amount of total $\mathrm{PAB}+\mathrm{PAH}$ plus the acetylated forms determined colorimetrically. This value minus the total $\mathrm{PAB}+\mathrm{PAH}$ represents the amount of acetylated forms in the serum.

\section{Determination in urine}

One ml. of properly diluted and filtered urine was pipetted into a colorimeter tube for analysis of total $\mathrm{PAB}+\mathrm{PAH}$. One $\mathrm{ml}$. of the same sample was added to $2 \mathrm{ml}$. of the buffer without $5 N \mathrm{NaOH}$ ( $\mathrm{pH} 3.85$ upon dilution of $2 \mathrm{ml}$. buffer with $1 \mathrm{ml}$. distilled water). Extraction of PAB and colorimetric analysis were performed as for serum and the amounts calculated for total hourly excretion.

\section{RESULTS}

Normal subjects: Data are presented in Figure 1 , illustrating the absorption, conjugation, and excretion of $\mathrm{PAB}$ in two normal subjects. These subjects also illustrate the extremes of normal

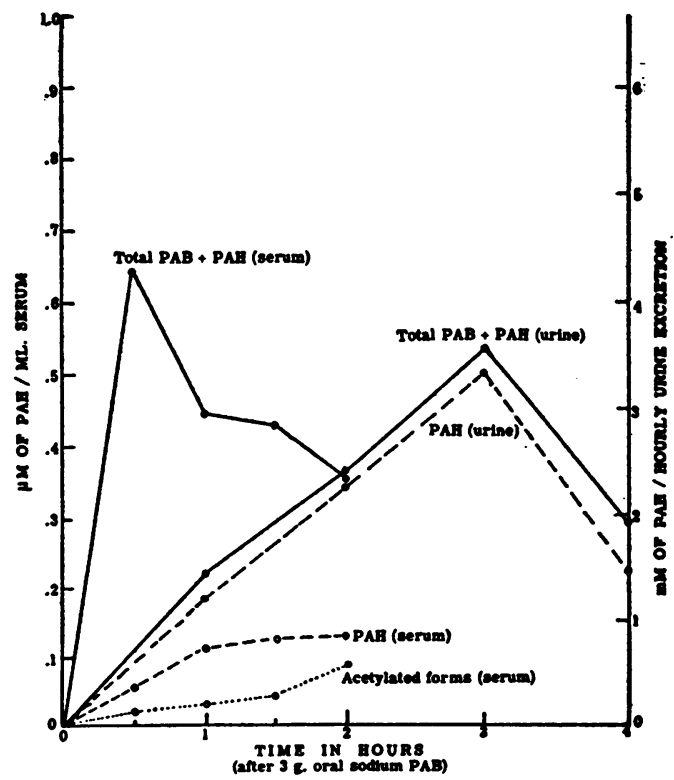

B

Fig. 1. Absorption, Conjugation, and Excretion of Pab in Two Normal Subjects, Illustrating the Extremes of Normal PAH Synthesis 
PAH synthesis. Absorption began rapidly, the serum levels reaching a peak at one-half hour. In some other normal subjects the peaks were reached between one-half and one and a half hours. Synthesis of PAH began early and reached a maximum between one to two hours. As this synthesis progressed, PAH was excreted into the urine and the serum levels of PAB decreased concomitantly. In one subject (Figure 1A) it will be noted that with an early relatively high serum $P A B$ level a greater amount of $\mathrm{PAB}$ appeared in the one hour urine specimen. However, PAH excretion exceeded that of PAB by a marked degree. Acetylation in these subjects progressed more slowly. In five other subjects the average amount of the acetylated form was $.06 \mu \mathrm{M} / \mathrm{ml}$. serum in the one hour specimen.

Figure 2 represents data on the 60 subjects comprising the normal group. The per cent of the total $\mathrm{PAB}+\mathrm{PAH}$ in the form of $\mathrm{PAH}$ in the serum at one hour varied inversely with the total $\mathrm{PAB}+\mathrm{PAH}$ in a consistent manner. The mean $\% \mathrm{PAH}$, at any level of total $\mathrm{PAB}+\mathrm{PAH}$, of this normal group was taken arbitrarily as $100 \%$ (S.D. $\pm 13.1)$. The mean \% PAH of the 14 organically sound subjects was somewhat higher

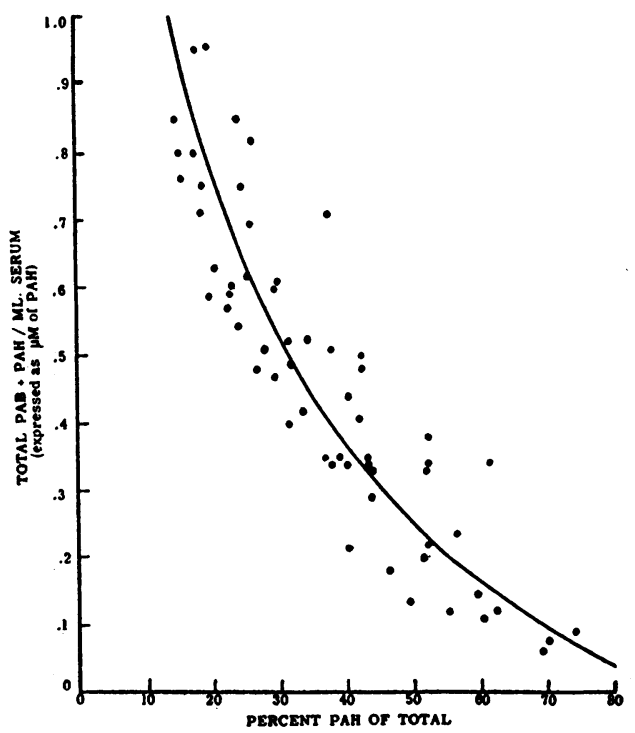

Fig.. 2. Relation of \% PAH of the Total to the Total PAB + PAH

The points represent PAH synthesis in one hour as determined in 60 normal subjects. The solid line represents the normal mean \% $\mathrm{PAH}$.
TABLE I

Analysis of results of PAH synthesis test in 101 hospital patients

\begin{tabular}{r|l|c|c}
\hline $\begin{array}{c}\text { Number } \\
\text { of cases }\end{array}$ & \multicolumn{1}{|c|}{ Diagnosis } & $\begin{array}{c}\text { Mean PAH } \\
\text { synthesis }\end{array}$ & $\begin{array}{c}\text { Standard } \\
\text { deviation }\end{array}$ \\
\cline { 2 - 4 } & & $\begin{array}{c}\% \text { of } \\
\text { normal } \\
\text { mean }\end{array}$ & \\
14 & No organic disease & 104 & 28.4 \\
46 & $\begin{array}{l}\text { Organic disease without liver } \\
\text { involvement }\end{array}$ & $\begin{array}{c}99.4 \\
\end{array}$ & 14.7 \\
\hline 60 & Total without liver involve- & 100 & 13.1 \\
& ment (normal) & & \\
\hline 7 & Obstructive jaundice & 84 & \\
3 & Metastatic carcinoma & 63.8 & \\
11 & Infectious mononucleosis & 60.4 & \\
3 & Thyrotoxicosis & 55.5 & \\
2 & Rheumatoid arthritis & 54.5 & \\
2 & Chronic ulcerative colitis & 33.7 & \\
13 & Primary liver disease & 30.7 & 9 \\
\hline
\end{tabular}

$(104 \% \pm 28.4)$ than the 46 with organic disease but without liver involvement $(99.4 \% \pm 14.7)$. This difference was directly attributable to marked increase in synthesis in two organically sound subjects with severe anxiety states $(170 \%$ and $147 \%$ of the normal mean).

Liver disease or impairment group: Complete data are presented in Tables I and II. The mean $\mathrm{PAH}$ synthesis in one hour of 13 patients with primary liver disease was $30.7 \%$ of the normal mean. Eight of these had atrophic cirrhosis, proven by biopsy or necropsy in six. The other two (Nos. 108 and 124) were clinically typical. Two cases of chronic hepatitis with cirrhosis were proven by biopsy. One patient had a single large purulent liver abscess at laparotomy. There was one case each of infectious hepatitis and homologous serum hepatitis, both in an active stage of disease. One patient (No. 24) with cirrhosis also had bacteriologically proven brucellosis. One week following what was considered successful therapy with aureomycin there was only slight improvement in PAH synthesis. Diagnosis in six of the cases of obstructive jaundice was confirmed by laparotomy. In the other case (No. 83) a diagnosis of pernicious anemia and cholelithiasis was made on clinical grounds and the jaundice attributed to the latter.

The three cases of metastatic carcinoma were proven by biopsy. One case of chronic ulcerative colitis (No. 9) was in a state of relative clinical remission, having recovered three months previ- 
TABLE II

Comparison of the PAH synthesis test with other liver function tests in 41 pathological cases

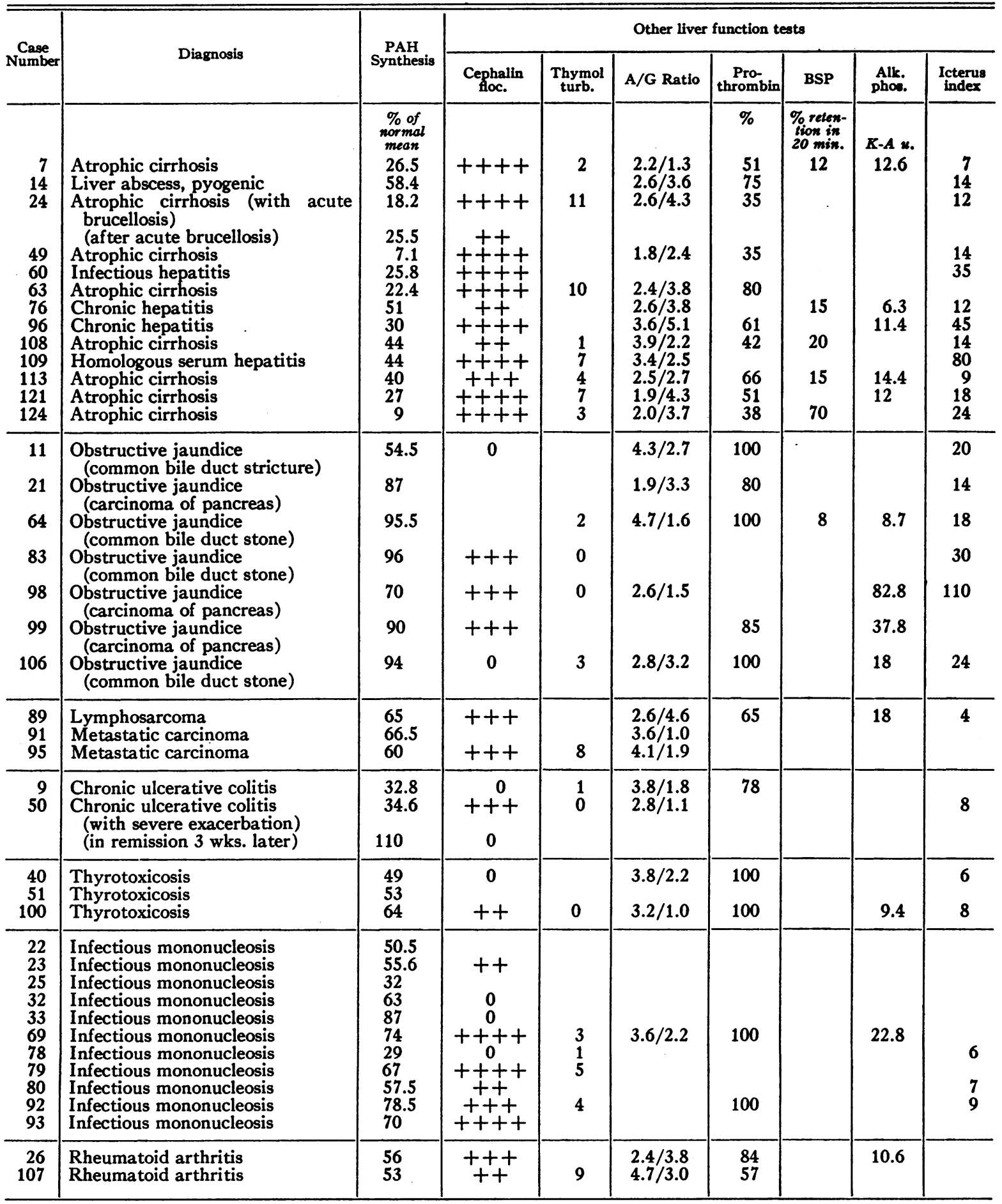


ously from a severe acute exacerbation. The low value of $\mathrm{PAH}$ synthesis $(32.8 \%)$ in this patient in remission is in contrast to the rapid improvement in PAH synthesis in case No. $50(34.6 \%$ during the acute severe exacerbation and $110 \%$ three weeks later following marked clinical improvement). The cases of thyrotoxicosis were typical and showed no evidence of liver impairment. The cases of infectious mononucleosis in various stages of illness were typical clinically and hematologically and in most instances showed a rising heterophile antibody titer.

Effect of glycine: The marked increase in $\mathrm{PAH}$ synthesis produced by administration of glycine to a normal subject is illustrated in Figure 3, and the synthesis at one hour of eight normal subjects given glycine is compared with the normal mean in Figure 4. The mean \% PAH of the normal glycine group parallels the mean $\% \mathrm{PAH}$ of the normal group without glycine. Five of the normal subjects in this group were studied several days previously without glycine. The values for their PAH synthesis compared closely to the two respective means.

The effect of glycine feeding on PAH synthesis in five cases of primary liver disease and one of thyrotoxicosis is shown in Table III. Increase in synthesis of $\mathrm{PAH}$, in terms of the normal mean without glycine, occurred in all cases except in the patient with homologous serum hepatitis (No. 109). The results of the two tests, one with and one without glycine, in the latter patient are not

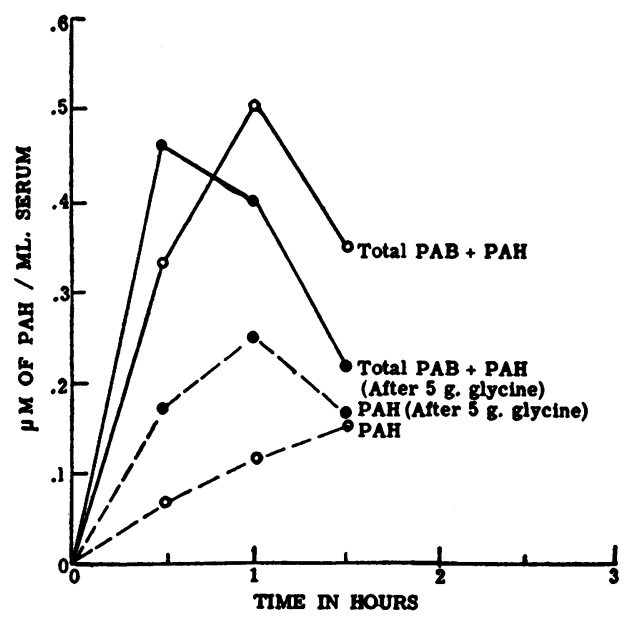

Fig. 3. Effect of Glycine Administration Upon PaH Synthesis in a Normal Subject

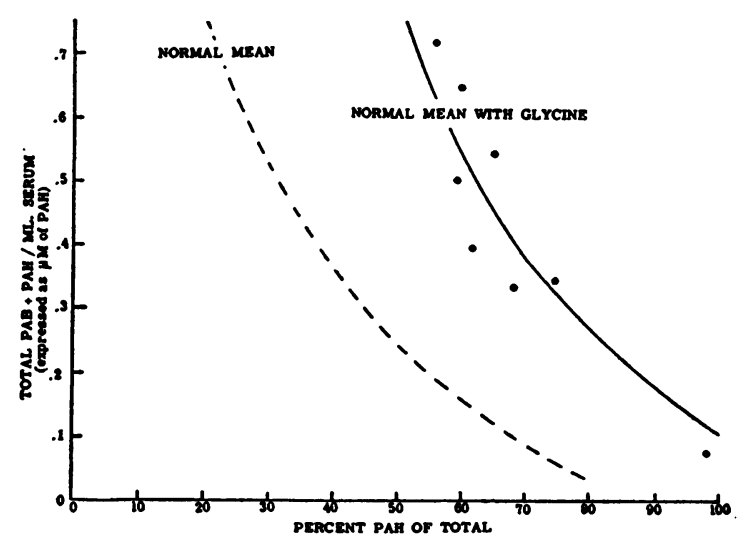

Fig. 4. Stimulation of PAH Synthesis by Glycine Administration With a Comparison of the Normal Means With and Without Glycine

comparable since there was a six day interval between them, and his clinical condition was changing. PAH synthesis, in terms of the normal glycine mean, remained distinctly abnormal in all five cases of primary liver disease. In the patient with thyrotoxicosis, however, $\mathrm{PAH}$ synthesis, in terms of the normal glycine mean, became normal following glycine feeding.

\section{DISCUSSION}

The data presented here on the absorption, conjugation, and excretion of PAB are in general accord with the investigations based on the renal clearances of PAB and PAH (9), and on the metabolism of similar doses of PAB (8), and represent ramifications of this work.

The inverse ratio of $\% \mathrm{PAH}$ to total $\mathrm{PAB}+$ $\mathrm{PAH}$ in the one hour serum specimens appears

TABLE III

Effect of oral glycine (5 g.) on PAH synthesis in patients with liver disease and thyrotoxicosis

\begin{tabular}{|c|c|c|c|c|}
\hline \multirow{3}{*}{$\begin{array}{c}\text { Case } \\
\text { number }\end{array}$} & & \multicolumn{3}{|c|}{ PAH synthesis } \\
\hline & & \multirow{3}{*}{$\begin{array}{c}\begin{array}{c}\text { Without } \\
\text { glycine }\end{array} \\
\begin{array}{c}\text { \%ormal } \\
\text { mean } \\
51\end{array}\end{array}$} & \multicolumn{2}{|c|}{ Glycine feeding } \\
\hline & & & $\%_{\text {mean }}^{\text {normal }}$ & $\begin{array}{c}\text { \% normal } \\
\text { glycine } \\
\text { mean }\end{array}$ \\
\hline 76 & $\begin{array}{l}\text { Chronic hepatitis } \\
\text { (hemochromatosis) }\end{array}$ & & 109 & 76 \\
\hline $\begin{array}{r}24 \\
109\end{array}$ & $\begin{array}{l}\text { Atrophic cirrhosis } \\
\text { Homologous serum } \\
\text { hepatitis }\end{array}$ & $\begin{array}{l}18 \\
44\end{array}$ & $\begin{array}{l}31.6 \\
36\end{array}$ & $\begin{array}{l}19 \\
18\end{array}$ \\
\hline $\begin{array}{r}121 \\
124 \\
40\end{array}$ & $\begin{array}{l}\text { Atrophic cirrhosis } \\
\text { Atrophic cirrhosis } \\
\text { Thyrotoxicosis }\end{array}$ & $\begin{array}{r}27 \\
9 \\
49\end{array}$ & $\begin{array}{r}46 \\
69 \\
200\end{array}$ & $\begin{array}{r}22 \\
44 \\
118\end{array}$ \\
\hline
\end{tabular}


to be due to variation in the rates and quantity of $\mathrm{PAB}$ absorption. It is, however, clear that this ratio is relatively constant (standard deviation = $13.1 \%$ for a normal mean of $100 \%$, representing the range of normal). It was also observed that in the same normal subjects on separate occasions a constant PAH synthesis in terms of $\%$ of the normal mean was maintained in spite of variation in total $\mathrm{PAB}+\mathrm{PAH}$.

The finding of increased PAH synthesis in two patients with severe anxiety states is in accord with the reported increased hippuric acid excretion in such patients (10).

The reduction in $\mathrm{PAH}$ synthesis in patients with liver disease was marked (mean $=30.7 \%$ of the normal mean) and significant, indicating the applicability of PAH synthesis as a liver function test. The results in obstructive jaundice were only slightly below the limits of normal, and suggest that the test is of value in the differential diagnosis of jaundice. The abnormal synthesis in infectious mononucleosis is consistent with evidence that liver damage is frequent in this disease $(11,12)$. Hepatic impairment is also known to occur with chronic ulcerative colitis $(13,14)$, and thyrotoxicosis (15).

The increase in $\mathrm{PAH}$ synthesis following glycine feeding in normal subjects was expected since an increase in hippuric acid synthesis has been shown to occur under similar conditions (16). Low plasma glycine levels have been reported in rheumatoid arthritis, chronic ulcerative colitis, and some cases of thyrotoxicosis, although uncommonly in the latter (17). The pronounced increase in $\mathrm{PAH}$ synthesis of the patient with thyrotoxicosis (No. 40) fed glycine may be related to this factor. The observation that PAH synthesis in patients with primary liver disease was increased by glycine feeding but remained abnormal with respect to the normal glycine mean would appear to indicate that here the actual synthetic mechanism was impaired.

Thus from the data presented, it is clear that $\mathrm{PAH}$ synthesis can be used as a test for liver function. The conditions as employed in this study appear to be suitable, viz., a $3 \mathrm{~g}$. dose of $\mathrm{PAB}$ orally followed by analysis of a blood sample one hour later. From the findings with glycine, it would appear desirable to include this in the test. Thus it is recommended that in setting up a stand- ard, the combined use of $3 \mathrm{~g}$. of PAB plus $5 \mathrm{~g}$. of glycine be employed.

Extensive comparison of this test with the hippuric acid test has not been carried out, but in four normal subjects and two with liver disease results of the two tests were comparable. In one other patient with carcinoma of the esophagus and bilateral renal calculi, in whom all other liver function tests were normal, the hippuric acid test gave abnormal results on two separate occasions ( $.32 \mathrm{~g}$. and $.50 \mathrm{~g}$. in one hour with the intravenous test) while the PAH synthesis was $104 \%$ of the normal mean, suggesting that poor renal function had impeded excretion of hippuric acid.

A competitive inhibition between $\mathrm{PAB}$ and benzoic acid for the PAH synthesizing enzyme has been shown (18). On an equimolar basis, benzoic acid inhibited synthesis of $\mathrm{PAH}$ from $\mathrm{PAB}$ to the extent of $60 \%$, indicating that the same enzyme system is concerned in the synthesis of PAH and hippuric acid. To test this in the human, a normal subject, whose previously determined $\mathrm{PAH}$ synthesis was $98 \%$ of the normal mean, was given $0.8 \mathrm{~g}$. of sodium benzoate intravenously ten minutes before a second PAH test. On this test PAH synthesis was only $39.2 \%$ of the normal mean, indicating that the same enzyme system is involved and that a competitive inhibition occurs in the human.

\section{SUM MARY}

1. Utilizing the usual diazo-coupling reaction for analysis of sulfonamides and ether extraction of $\mathrm{PAB}$, the metabolism of orally administered PAB was studied in the serum and urine of humans.

2. One hour serum levels of $P A B$ and $P A H$ were determined in 101 subjects. Values for PAH synthesis in 60 normal subjects were found to fall within a well defined range. Values for PAH synthesis in 13 patients with primary liver disease were consistently below the normal range. Impairment of synthesis was noted in three patients with secondary malignancy of the liver, two cases of chronic ulcerative colitis, three cases of thyrotoxicosis, two cases of rheumatoid arthritis, and 10 of 11 cases of infectious mononucleosis. PAH synthesis was normal in five of seven patients with obstructive jaundice, slightly decreased in one, and abnormal in the seventh. 
3. These findings indicate that $\mathrm{PAH}$ synthesis, as measured by serum levels of $\mathrm{PAH}$, is a useful test for liver function. The mechanism of $\mathrm{PAH}$ synthesis appears to be identical with that of hippuric acid synthesis but minimizes the need for evaluating renal function in the latter test.

4. Administration of glycine appreciably increased $\mathrm{PAH}$ synthesis in eight normal subjects. The effect of glycine feeding in patients with liver disease is discussed.

\section{BIBLIOGRAPHY}

1. Cohen, P. P., and McGilvery, R. W., Peptide bond synthesis. I. The formation of $p$-aminohippuric acid by rat liver slices. J. Biol. Chem., 1946, 166, 261.

2. Cohen, P. P., and McGilvery, R. W., Peptide bond synthesis. II. Formation of $p$-aminohippuric acid by liver homogenates. J. Biol. Chem., 1947, 169, 119.

3. Cohen, P. P., and McGilvery, R. W., Peptide bond synthesis. III. On the mechanism of p-aminohippuric acid synthesis. J. Biol. Chem., 1947, 171, 121.

4. Quick, A. J., The synthesis of hippuric acid; a new test of liver function. Am. J. M. Sc., 1933, 185, 630.

5. Quick, A. J., Clinical application of the hippuric acid and prothrombin tests. Am. J. Clin. Path., 1940, 10, 222.

6. Popper, H., and Steigmann, F., Differential diagnosis between medical and surgical jaundice by laboratory tests. Ann. Int. Med., 1948, 29, 469.

7. Steigmann, F., Popper, H., and Meyer, K. A., Liver function tests in clinical medicine. J. A. M. A., 1943, 122, 279.
8. Smith, P. K., Bayliss, J. R., Orgorzalek, S., and McClure, M. M., Metabolism of large doses of para-aminobenzoic acid. Federation Proc., 1946, 5, 154.

9. Smith, H. W., Finkelstein, N., Aliminosa, L., Crawford, B., and Graber, M., The renal clearances of substituted hippuric acid derivatives and other aromatic acids in the dog and man. J. Clin. Invest., 1945, 24, 388.

10. Persky, H., Grinker, R. R., and Mirsky, I. A., The excretion of hippuric acid in subjects with free anxiety. J. Clin. Invest., 1950, 29, 110.

11. Brown, J. W., Sims, J. L., White, E., and Clifford, J. E., Liver function during infectious mononucleosis. Am. J. Med., 1949, 6, 321.

12. Evans, A. S., Liver involvement in infectious mononucleosis. J. Clin. Invest., 1948, 27, 106.

13. Ross, J. R., and Swarts, J. M., Hepatic dysfunction and cirrhosis in chronic ulcerative colitis. Gastroenterology, 1948, 10, 81.

14. Tumen, H. J., Monaghan, J. F., and Jobb, E., Hepatic cirrhosis as a complication of chronic ulcerative colitis. Ann. Int. Med., 1947, 26, 542.

15. Bartels, E. C., and Perkin, H. J., Liver function in hyperthyroidism as determined by the hippuric acid test. New England J. Med., 1937, 216, 1051.

16. de Vries, A., and Alexander, B., Studies on amino acid metabolism. III. Plasma glycine concentration and hippuric acid formation following the ingestion of benzoate. J. Clin. Invest., 1948, 27, 665.

17. de Vries, A., and Alexander, B., Studies on amino acid metabolism. II. Blood glycine and total amino acids in various pathological conditions with observations on the effects of intravenously administered glycine. J. Clin. Invest., 1948, 27, 655.

18. Cohen, P. P., and McGilvery, R. W., Unpublished data. 